people, perhaps six months or more for those with no speech (how many consultants are fluent in makaton?).

Do we pay enough attention to the emotional aspects of mental handicap? Do we address the emotional stress of dealing with profoundly handicapped physically disabled individuals? How can you build up a meaningful psycho-therapeutic relationship with someone who spits and bites? (Unwillingness to engage in therapy for registrars may be as a result of their unconscious rejection feelings.) We need to recognise these feelings.

Registrars should have a range of experience in mental handicap and be involved in the care of patients with challenging behaviour, learning how this challenges the service. Training should include experience in case conferences, community homes, out-patient clinics, resettlement, forensic/prison visits, adult training centres, drug reviews, psychotherapy with the mentally handicapped, management of epilepsy and community mental handicap teams (CHMTs). Visiting community homes, and learning to support the staff there and 'drinking tea' with the residents, should be an integral part of training. The CMHT is also valuable teaching, although this can feel like wasted time if there are endless meetings talking about patients you do not know, or administrative matters. Do registrars go on home visits with the community nurses? There should be time spent with patients families learning how to support and counsel them. A few basics to community psychiatry are: long-range bleep, good secretarial support, map, car, dictating machine. How many registrars get all these?

How to give registrars community experience in mental handicap while still covering the on-call for the large hospital can be overcome. Also, we need to ensure that registrars learn to recognise and treat mental illness in mental handicap.

South Ockendon Hospital

JULIA SANDERS South Ockendon, Essex

\section{Mental Health Review Tribunals}

\section{DeAR Sirs}

I am concerned about the continued reduction of psychiatric services on financial grounds and the persistent demand for cost improvements. One area to look at for savings might well be the Mental Health Review Tribunal system.

The 1983 Mental Health Act introduced the concept of Mental Health Review Tribunals and the right of patients' legal representation. These hearings I would suspect cost at least $£ 1,000$ a time, yet the patient can obtain legal representation no matter how hopeless his chances are.
The normal position with regard to Legal Aid is that it can only be obtained if there is a reasonable chance of success but the Mental Health Review Tribunal system ignores this.

It would be interesting to know the cost of the hearings and what savings might accrue should Legal Aid be restricted to those hearings where the patient has some hope of success.

I appreciate the fact that someone has to decide whether or not the patient has the likelihood of discharge but this should not be too difficult a problem to overcome.

\section{Mental Health Unit \\ St Crispin Hospital \\ Duston, Northampton NN5 6UN}

\section{Seclusion of psychiatric patients}

\section{DeAr SirS}

I read with great interest the statement on the seclusion of psychiatric patients (Psychiatric Bulletin, $1990,14,754-6)$ and support most of the statements therein. However, I was concerned by the very strict definition of seclusion which you use. In our hospital, we define seclusion as "the enforced isolation of any patient". This includes situations where, for instance, a patient is locked alone in a confined courtyard, or a disabled patient is shut in an unlocked room from where they are unable to exit unaided, despite the door being technically unlocked.

The reasons behind this broadening of the definition were, of course, to eliminate the loopholes in the procedures whereby alternative methods of de facto seclusion could be used to circumvent proper procedures. We feel that using our broader definition, all potential situations of isolation are covered by proper procedures, and subject to proper control.

\section{The Otago Area Health Board \\ Cherry Farm Hospital \\ Dunedin, New Zealand}

N. R. JUDSON

\section{Transcultural misunderstandings}

\section{DeAr Sirs}

The article by Appleby \& Beaton (Psychiatric Bulletin, November 1990, 14, 671-673) was both interesting and informative. The area of communication effectiveness is of vital importance in psychiatry, where comprehension of the patient's history is central to the diagnostic process. This particular problem was brought to our attention recently when a man, of Central American origin, was transferred to our hospital on certificates, for treatment of a 'paranoid psychosis with auditory hallucinations'. As the patient spoke Spanish, a colleague interviewed him 